\title{
ON SOME INEQUALITIES CONCERNING RELATIVE $(p, q)-\varphi$ TYPE AND RELATIVE $(p, q)-\varphi$ WEAK TYPE OF ENTIRE OR MEROMORPHIC FUNCTIONS WITH RESPECT TO AN ENTIRE FUNCTION
}

\author{
TANMAY BISWAS
}

Abstract. The main aim of this paper is to study some growth properties of entire and meromorphic functions on the basis of relative $(p, q)-\varphi$ type and relative $(p, q)-\varphi$ weak type of entire and meromorphic function with respect to an entire function.

Mathematics subject classification (2010): 30D20, 30D30, 30D35.

Keywords and phrases: Entire function, meromorphic function, relative $(p, q)-\varphi$ order, relative $(p, q)$ $\varphi$ type, relative $(p, q)-\varphi$ weak type growth.

\section{REFERENCES}

[1] L. Bernal, Crecimiento relativo de funciones enteras. Contribución al estudio de lasfunciones enteras coníndice exponencial finito, Doctoral Dissertation, University of Seville, Spain, 1984.

[2] L. Bernal, Orden relative de crecimiento de funciones enteras, Collect. Math. 39, (1988), 209-229.

[3] T. BISWAS, On some growth analysis of entire and meromorphic functions in the light of their relative $(p, q, t) L$-th order with respect to another entire function, An. Univ. Oradea, fasc. Mat., accepted for publication, 2018.

[4] L. Debnath, S. K. Datta, T. Biswas And A. Kar, Growth of meromorphic functions depending on $(p, q)$-th relative order, Facta Univ. Ser. Math. Inform. 31, 3 (2016), 691-705.

[5] S. K. DATTA AND T. BISWAS, Growth estimates of entire functions with the help of their relative $L^{*}$-types and relative $L^{*}$-weak types, Commun. Fac. Sci. Univ. Ank. Sér. A1 Math. Stat. 68, 1 (2019), $136-148$.

[6] S. K. DATTA AND T. BISWAS, Comparative growth analysis of entire and meromorphic functions using their relative types and relative weak types, Eurasian Math. J. 8, 4 (2017), 35-44.

[7] S. K. DATTA AND T. BISWAS, On the generalized relative type and generalized relative weak type related growth analysis of entire functions, J. Fract. Calc. Appl. 8, 2 (2017), 101-113.

[8] S. K. DATTA AND T. BISWAS, Measure of growths of entire functions from the view point of their relative $L^{*}$-type and relative $L^{*}$-weak type, Palest. J. Math. 6, (Special Issue: II) (2017), 149-156.

[9] S. K. DatTA AND T. Biswas, Some results on generalized relative type and generalized relative weak type of entire functions, Aligarh Bull. Math. 35, 1-2 (2016), 39-54.

[10] S. K. DATTA AND T. BISWAS, On the measurement of growth properties of entire and meromorphic functions focusing their relative type and relative weak type, Facta Univ. Ser. Math. Inform. 31, 5 (2016), 1011-1028.

[11] S. K. DatTA, T. Biswas AND D. DutTa, Generalized relative type and generalized weak type of entire functions, J. Complex Anal., Volume 2016, Article ID 3468354, 1 pages, http: //dx.doi .org/ $10.1155 / 2016 / 3468354$.

[12] W. K. Hayman, Meromorphic Functions, The Clarendon Press, Oxford (1964).

[13] O. P. JuneJa, G. P. KAPOOR AND S. K. BAJPAI, On the $(p, q)$-order and lower $(p, q)$-order of an entire function, J. Reine Angew. Math. 282, (1976), 53-67.

[14] I. Laine, Nevanlinna Theory and Complex Differential Equations, De Gruyter, Berlin, 1993.

[15] B. K. LAhiRI AND D. BANERJEe, Relative order of entire and meromorphic functions, Proc. Nat. Acad. Sci. India Ser. A., 69 (A), 3 (1999), 339-354. 
[16] L. M. S. Ruiz, S. K. Datta, T. Biswas And G. K. Mondal, On the (p,q)-th relative order oriented growth properties of entire functions, Abstr. Appl. Anal., Volume 2014, Article ID 826137, 8 pages, http://dx.doi.org/10.1155/2014/826137.

[17] D. SATO, On the rate of growth of entire functions of fast growth, Bull. Amer. Math. Soc. 69, (1963), $411-414$.

[18] X. Shen, J. Tu AND H. Y. XU, Complex oscillation of a second-order linear differential equation with entire coefficients of $[p, q]-\varphi$ order, Adv. Difference Equ. 2014,2014: 200, 14 pages, http://www .advancesindifferenceequations. com/content/2014/1/200.

[19] L. YANG, Value distribution theory, Springer-Verlag, Berlin, 1993.

[20] G. VAliron, Lectures on the general theory of integral functions, Chelsea Publishing Company, 1949. 